\title{
Hubungan Kecerdasan Emosi dan Pola Asuh Demokratis dengan Strategi Coping Adaptif pada Mahasiswa Tingkat Akhir
}

\section{The Relationship of Emotional Intelligence and Democratic Parenting with Adaptive Coping Strategies for Final Year Students}

\author{
Maria Fella Thika Sary \& Nefi Damayanti \\ Magister Psikologi, Universitas Medan Area Indonesia
}

\begin{abstract}
Abstrak
Penelitian ini bertujuan untuk mengetahui hubungan antara kecerdasan emosi dengan strategi coping adaptif, hubungan pola asuh demokratis dengan strategi coping adaptif, dan hubungan antara kecerdasan emosi dan pola asuh demokratis dengan strategi coping adaptif pada mahasiswa tingkat akhir. Populasi dalam penelitian ini adalah mahasiswa tingkat akhir di Fakultas Psikologi Universitas Medan Area. Sampel penelitian berjumlah 74 mahasiswa yang diambil dengan teknik purposive sampling. Instrumen yang digunakan adalah skala kecerdasan emosi, skala pola asuh demokratis dan skala strategi coping adaptif. Hasil analisis regresi berganda menunjukkan nilai $F_{\text {reg }}$ sebesar 469,324 dengan $p=0,000(p<0,005)$ hal tersebut menunjukkan bahwa terdapat hubungan yang signifikan antara kecerdasan emosi dan pola asuh demokratis dengan strategi coping adaptif. Secara parsial, terdapat hubungan antara kecerdasan emosi dengan strategi coping adaptif dengan $r_{x 1 y}=0,936$ dengan $p<0,00$, serta terdapat hubungan antara pola asuh demokratis dengan strategi coping adaptif $r_{x 2 y}=0,920$ dengan $p<0,00$. Nilai $\mathrm{R}^{2}$ sebesar 0,933 artinya kecerdasan emosi dan pola asuh demokratis secara bersama-sama memberi sumbangan efektif sebesar 93,3\% terhadap strategi coping adaptif.

Kata Kunci: Kecerdasan Emosi, Pola Asuh Demokratis, Strategi Coping Adaptif.
\end{abstract}

Abstract
This research aims to know the relationship between emotional intelligence with Adaptive coping strategies, relationships with democratic parenting and adaptive coping strategies and the relationship between emotional intelligence and democratic parenting with Adaptive coping strategies on senior students. The population in this research is the senior students at the Faculty of psychology of the University of Medan Area. Sample research amounted to 74 students were taken with purposive sampling technique. The instruments used are emotional intelligence scale, parenting democratic scale and adaptive coping strategy scale. Results of multiple regression analysis shows amounted to 469.324 with $F_{\text {reg }}$ value $p=0.000(p<0.005)$ it shows that there is a significant relationship between emotional intelligence and democratic parenting with adaptive coping strategies. Partially, there is the relationship between emotional intelligence with adaptive coping strategies with $r x y=0.000 .936$ with $p<$, and there is a relationship between democratic parenting with adaptive coping strategies rxy $=0.920$ with $p<0.00$. The value of R2 of 0.933 emotional intelligence means and foster democratic patterns together contributed effectively amounted to $93.3 \%$ against adaptive coping strategies.

Keywords: Emotional Intelligence, Democratic Parenting, Adaptive Coping Strategies.

How to Cite: Sary, M. F. T., \& Damayanti, N. (2019). Hubungan Kecerdasan Emosi dan Pola Asuh Demokratis dengan Strategi Coping Adaptif pada Mahasiswa Tingkat Akhir. Tabularasa: Jurnal Ilmiah Magister Psikologi, 1(2) 2019: 191-197,

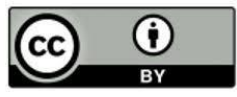


Sary, M. F. T., \& Nefi Damayanti, N. Hubungan Kecerdasan Emosi dan Pola Asuh Demokratis dengan ...

\section{PENDAHULUAN}

Setiap manusia memiliki masalah didalam hidupnya tidak terkecuali pada mahasiswa. Ketika memasuki perguruan tinggi mahasiswa diberi target untuk menyelesaikan studi mereka. Masa studi yang harus ditempuh oleh mahasiswa biasanya 4-5 tahun, akan tetapi perguruan memberi kemudahan agar dapat menyelesaikan masa studi hanya dalam jangka waktu 3,5 tahun. Oleh karena itu mahasiswa khususnya mahasiswa tingkat akhir harus dapat menyeimbangkan antara menyelesaikan tugas dan mengerjakan skripsi agar dapat menyelesaikan masa kuliah dengan lebih cepat. Mahasiswa yang memiliki kecerdasan emosi yang tinggi tentunya dapat mengatasi setiap permasalahan yang sedang dihadapinya. Mahasiswa yang dapat menyelesaikan masalahnya dengan jalan yang positif maka dia mempunyai strategi coping adaptif yang baik.

Hubungan antara strategi coping adapatif dengan kecerdasan emosi diungkapkan oleh Salovey dan Meyer, bahwa seseorang yang memiliki kecerdasan emosi yang tinggi akan mampu menguasai situasi yang penuh tantangan, yang mampu menimbulkan ketegangan dan kecemasan. Orang yang memiliki kecerdasan emosi yang tinggi akan lebih tangguh dalam menghadapi berbagai persoalan hidup dan mampu mengasimilasi tingkat stress yang tinggi (Isnainy \& Alfita, 2017).

Pembentukan strategi coping adaptif yang baik pada mahasiswa tentunya tidak lepas dari pola asuh orangtua. Sebab pola asuh orangtua yang baik akan mendukung perkembangan seorang anak. Pola asuh itu sendiri merupakan perilaku yang nampak ketika orangtua melakukan komunikasi dan membangun hubungan secara emosi kepada anaknya. Menurut Wolfaardt dkk (2003), pola asuh orangtua yang bersifat hangat dan khusus memiliki hubungan terhadap pemilihan strategi coping yang akan digunakan oleh seorang individu. Hal ini karena kehangatan yang ditunjukkan oleh orangtua begitu pula dengan kontrol yang ditunjukkan oleh orangtua sehingga mempengaruhi kemampuan adaptasi seorang anak terhadap penyelesaian masalahnya (Pandia, et al., 2015; Hartaty \& Azis, 2014; Novita, 2012; Hasmayani, 2012; Salamiah et al., 2011).

Pola asuh orangtua yang menerapkan kehangatan adalah pola asuh demokratis. Orangtua dengan pola asuh demokratis akan mengarahkan seorang anak dalam hal ini adalah mahasiswa secara rasional dan berorientasi pada isu-isu permasalahan. Orangtua juga berfokus pada kualitas remaja dan menentukan standar perilaku menggunakan alasaan, kekuatan dan kekuasaaan tanpa langsung memenuhi keinginan anak.

Selain membantu dalam proses pembentukan strategi coping adaptif yang baik pada mahasiswa pola asuh demokrtis juga dapat membuat seorang mahasiswa mempunyai tingkat kecerdasan emosi yang tinggi (Hamdani, et al., 2015; Zuraida, et al., 2015; Harahap, et al., 2014; Syarifah \& Darmayanti, 2010; Siregar, 2012). Hal ini disebabkan karena dalam pembuatan kebijakan orangtua menggunakan komunikasi dua arah dengan anak sehingga anak dapat menyampaikan pendapatnya dan orangtua dapat mendengarkan pendapat tersebut. Standar perilaku dan kebijakan yang telah dibentuk serta komunikasi dua arah yang digunakan oleh orangtua pada pola asuh demokratis dapat membantu mahasiswa dalam meningkatkan kecerdasan emosi. Pada pola asuh demokratis orangtua mendukung sikap positif yang dilakukan oleh anak dalam hal ini mahasiswa dalam menghadapai 
kendala-kendala ketika menyelesaikan skripsi dan tugas-tugas yang menumpuk. Apabila mahasiswa dapat segera menyelesaikannya maka individu tersebut dapat lulus kuliah lebih cepat yaitu hanya dengan waktu 3,5 tahun.

Adapun tujuan penelitian dari penelitian ini secara umum adalah penelitian ini diharapkan dapat memberi kontribusi terhadap perkembangan ilmu psikologi, khususnya psikologi perkembangan dan psikologi klinis yang berkaitan dengan faktor-faktor dalam variabel strategi coping adaptif, kecerdasan emosi dan pola asuh demokratis, selain itu diharapkan mahasiswa psikologi terutama bagi mahasiswa tingkat akhir yang sedang menyusun skripsi penelitian ini dapat menerapkan ilmunya dalam menyelesaikan permasalahan yang dihadapi dalam menyelesaikan skripsi dan tugas-tugas agar dapat lulus lebih cepat yaitu 3,5 tahun. Selanjutnya secara khusus penelitian ini bertujuan untuk melihat (1) Hubungan strategi coping adaptif dengan kecerdasan emosi pada mahasiswa tingkat akhir di Fakultas Psikologi Universitas Medan Area? (2) Hubungan strategi coping adaptif dengan pola asuh demokratis pada mahasiswa tingkat akhir di Fakultas Psikologi Universitas Medan Area? (3) Hubungan antara kecerdasan emosidengan pola asuh demokratis pada mahasiswa tingkat akhir di Fakultas Psikologi Universitas Medan Area?

\section{METODE PENELITIAN}

Dalam penelitian ini peneliti menggunakan metode deskriptif kuantitatif dan menggunakan kuesioner sebagai alat pengumpul data. Adapun yang menjdai objek penelitian ini adalah para mahasiswa tingkat akhir di Fakultas Psikologi Universitas Medan Area. Adapun populasi dari penelitian ini adalah seluruh mahasiswa semester akhir di Fakultas Psikologi Universitas Medan Area yang berjumlah 126 orang. Menurut Hadi (2000) sampel merupakan sebagian dari populasi yang dipilih dengan menggunakan prosedur tertentu sehingga diharapkan mewakili populasinya. Oleh karena itu, sampel yang yang sesuai untuk digunakan dalam penelitian ini adalah mahasiswa semester akhir sebesar 74 orang. Teknik pengambilan sampel menggunakan teknik purposive sampling, yaitu teknik untuk menentukan sampel penelitian dengan beberapa pertimbangan tertentu. Dalam purposive sampling pemilihan sekelompok mempunyai hubungan yang erat dengan ciri-ciri atau karakteristik populasi yang sudah diketahui sebelumnya ( Hadi, 1994). Adapun kriteria-kriteria sampel dalam penelitian ini adalah (1)Mahasiswa akhir, (2) Mahasiswa yang sudah seminar hasil, (3) Mahasiswa yang diasuh secara demokratis oleh orang tuanya.

Metode pengumpulan data yang digunakan dalam penelitian ini adalah dengan menggunakan metode skala.

a. Skala Kecerdasan Emosi

Skala kecerdasan emosi dalam penelitian ini disusun berdasarkan aspek-aspek kecerdasan emosi yang dikemukakan oleh Goleman (2001) yakni aspek mengenali emosi, aspek memotivasi diri, aspek mengenali emosi orang lain, dan aspek membina hubungan. Berdasarkan hasil uji coba skala kecerdasan emosi yang berjumlah 64 butir, maka diketahui terdapat 27 item yang gugur.

b. Skala Pola asuh demokratis 
Sary, M. F. T., \& Nefi Damayanti, N. Hubungan Kecerdasan Emosi dan Pola Asuh Demokratis dengan ...

Skala ini disusun berdasarkan bentuk - bentuk aspek-aspek pola asuh demokratis, yaitu sikap hangat orangtua, adanya komunikasi dua arah antara anak dan orangtua, dukungan perkembangan individualitas remaja dari orangtua, dan penerapan aturan. Berdasarkan hasil uji coba skala pola asuh demokratis yang berjumlah 40 butir, maka diketahui terdapat 7 item yang gugur.

c. Skala strategi coping adaptif

Skala ini disusun berdasarkan aspek - aspek yang mempengaruhi strategi coping adaptif yaitu aspek Keaktifan diri, Keaktifan diri, perencanaan, kontrol diri, mencari dukungan sosial yang bersifat instrumental, mencari dukungan sosial yang bersifat emosional, dan religiusitas. Berdasarkan hasil uji coba skala strategi coping adaptif yang berjumlah 58 butir, maka diketahui terdapat 22 item yang gugur.

\section{HASIL DAN PEMBAHASAN}

Teknik analisis data yang digunakan dalam penelitian ini adalah analisis regresi berganda, dimana teknik ini akan melihat hubungan kecerdasan emosi dan pola asuh demokratis dengan strategi coping adaptif pada mahasiswa tingkat akhir, dalam penelitian ini adalah mahasiswa Fakultas Psikologi Universitas Medan Area. Namun sebelum data dianalisis regresi berganda, terlebih dahulu dilakukan uji asumsi terhadap variabel yang menjadi pusat perhatian.

Uji normalitas sebaran ini adalah untuk membuktikan bahwa penyebaran data penelitian telah menyebar berdasarkan prinsip kurva normal. Uji normalitas sebaran dianalisis dengan menggunakan formula Kolmogrov_Smirnov Test. Berdasarkan analisis tersebut maka diketahui bahwa berdistribusi sesuai dengan prinsip kurva normal. Sebagai kriteria apabila $p>0,050$ maka seberannya dinyatakan normal, sebaliknya apabila $\mathrm{p}>0,050$ sebarannya dinyatakan tidak normal ( Hadi, 2000). Dari hasil analisis uji normalitas untuk kecerdasan emosi dengan nilai $\mathrm{p}=$ 0,962 > 0,05 yang artinya kecerdasan emosi berdistribusikan normal. Untuk pola asuh demokratis dengan nilai $\mathrm{p}=0,801>0,05$ yang artinya pola asuh demokratis berdistribusikan normal. dan strategi coping adaptif dengan nilai $p=0,969>0,05$ yang artinya strategi coping adaptif berdistribusikan normal.

Uji linieritas hubungan dimaksud untuk melihat derajat hubungan variabel bebas dengan variabel terikat mempunyai hubungan yang terikat. Artinya apakah kecerdasan emosional dan pola asuh demokratis dapat menerangkan timbulnya strategi coping adaptif. Hal ini secara visualisasi dapat diterangkan dengan melihat garis linieritas, yaitu meningkatnya atau menurunnya nilai sumbu Y (Strategi Coping Adaptif) seiring dengan meningkatnya atau menurunnya nilai sumbu masing-masing variabel bebas (kecerdasan emosional dan pola asuh demokratis). Sebagai kriterianya apabila $\mathrm{p}<0,05$ maka dinyatakan mempunyai derajat hubungan linier (Hadi, 1986). Berdasarkan uji linieritas, maka diketahui bahwa kecerdasan emosi emosi terhadap strategi coping adaptif memiliki hubungan yang linier sedangkan pola asuh demokratis terhadap strategi coping adaptif memiliki hubungan yang linier.

Berdasarkan hasil analisis yang menggunakan analisis regresi berganda, diketahui bahwa terdapat kontribusi yang signifikan antara kecerdasan emosi (X1) dan pola asuh demokratis (X2) terhadap strategi coping adaptif $(Y)$. Hal ini ditujukan dengan nilai koefisien $F_{\text {reg }}=469,324 ; p=$ 0,000 dimana $\mathrm{p}<0,05$. Berdasarkan kriteria tersebut maka diketahui bahwa hipotesis penelitian ini dinyatakan diterima, dengan kata lain bahwa terdapat hubungan positif yang signifikan antara 
kecerdasan emosional dan pola asuh demokratis terhadap strategi coping adaptif. Berdasarkan kriteria tersebut maka diketahui bahwa hipotesis penelitian ini dinyatakan diterima, dengan kata lain bahwa ada hubungan positif yang signifikan antara kecerdasan emosi dan pola asuh demokratis dengan strategi coping adaptif. Berikut adalah rangkuman hasil pehitungan analisis regresi berganda. Diketahui koefisien korelasi antara $\mathrm{X}_{1}$-Y sebesar 0,876 yang artinya ada 87,6\% kecerdasan emosi mempengaruhi strategi coping adaptif, Diketahui koefisien korelasi antara $\mathrm{X}_{2}$ Y sebesar 0,846 yang artinya ada 84,6\% pola asuh demokratis mempengaruhi strategi coping adaptif dan secara bersama-sama kecerdasan emosi dan pola asuh demokratis memiliki daya prediksi terhadap munculnya strategi coping adaptifyang ditunjukan oleh koefisien $\mathrm{r}^{2}$ sebesar 0,933.Hal tersebut memberi makna bahwa secara bersama kedua variabel tersebut, yaitu kecerdasan emosi dan pola asuh demokratis menentukan munculnya strategi coping adaptifsebesar 93,3\%.

\section{Hasil perhitungan mean hipotetik dan Mean Empirik. Mean Hipotetik}

Pada variabel kecerdasan emosional dalam penelitian ini memiliki jumlah item sebanyak 44 yang diformat dengan skala Likert dalam 4 pilihan jawaban, maka mean hipotetiknya adalah $\{(37$ X 1) $+(37$ X 4) $\}: 2=92.5$. Pada variabel pola asuh demokratis memiliki jumlah item sebanyak 33 yang diformat dengan menggunakan skala Likert dalam 4 pilihan jawaban, maka mean hipotetiknya adalah $\{(33 \times 1)+(33 \times 4)\}: 2=82,5$.Selanjutnya variabel strategi coping adaptif dalam penelitian ini memiliki jumlah item 35 yang juga diformat dengan skala Likert dalam 4 jawaban, maka mean hipotetiknya adalah $\{(35 \times 1)+(35 \times 4)\}: 2=87,5$.

\section{Mean Empirik}

Berdasarkan analisis data, seperti yang terlihat dari uji normalitas sebaran diketahui bahwa mean empirik variabel kecerdasn emosi adalah $(94,29)$, variabel pola asuh demokratis memiliki mean empirik sebesar $(100,33)$ dan variabel startegi coping adaptif memiliki mean empirik sebesar (126,33).

\section{Pembahasan}

Berdasarkan hasil perhitungan, terdapat hubungan positif yang signifikan antara kecerdasan emosi dan pola asuh demokratis dengan strategi coping adaptif. Hal ini ditunjukan dengan koefisien $\mathrm{F}_{\text {reg }}=469.324 ; \mathrm{p}=0,000$ dimana $\mathrm{p}<0,050$. Menandakan bahwa semakin tinggi kecerdasan emosi dan pola asuh demokratis maka akan semakin tinggi pula strategi coping adaptif mahasiswa. Berdasarkan hasil penelitian ini, maka hipotesis yang diajukan dinyatakan diterima. Ada hubungan positif yang signifikan antara kecerdasan emosi dengan pola asuh demokratis pada mahasiswa di Fakultas Psikologi Universitas Medan Area dengan sumbangan 87,6 \%. Ada hubungan positif yang signifikan antara pola asuh dengan strategi coping adaptif mahasiswa, dengan sumbangan efektif yang didapatkan sebesar 84,6\%. Total sumbangan efektif dari kedua variabel bebas ( kecerdasan emosi dan pola asuh demokratis) terhadap strategi coping adaptif adalah sebesar 93,3\%. Dari hasil ini diketahui bahwa masih terdapat 6,7\% sumbangan dari faktor lain terhadap strategi coping adaptif.

Temuan penelitian ini sejalan dengan pendapat yang dikemukakan oleh Salovey dan Meyer yang mengungkapkan bahwa seseorang yang memiliki kecerdasan emosi yang tinggi akan 
Sary, M. F. T., \& Nefi Damayanti, N. Hubungan Kecerdasan Emosi dan Pola Asuh Demokratis dengan ...

mampu menguasai situasi yang penuh tantangan, yang mampu menimbulkan ketegangan dan kecemasan. Orang yang memiliki kecerdasan emosi yang tinggi akan lebih tangguh dalam menghadapi berbagai persoalan hidup dan mampu mengasimilasi tingkat stress yang tinggi. Oleh karena itu strategi coping adapatif memiliki hubungan yang erat dengan kecerdasan emosi. Seperti uraian diatas, temuan penelitian ini juga menjelaskan bahwa kecerdasan emosi memiliki hubungan positif yang signifikan dengan strategi coping adaptif dengan bobot sumbangan efektif sebesar $87,6 \%$. Selain itu pola asuh demokratis juga memiliki hubungan yang erat dengan strategi coping adaptif dengan bobot sumbangan efektif sebesar $84,6 \%$.

\section{SIMPULAN}

Berdasarkan hasil analisis dari pembahasan maka hal-hal yang dapat peneliti simpulkan adalah terdapat hubungan positif yang signifikan antara kecerdasan emosi dan pola asuh demokratis dengan strategi coping adaptif. Hal ini ditunjukan dengan koefisien $F_{\text {reg }}=469.324 ; p=0,000$ dimana $p<0,050$. Menandakan bahwa semakin tinggi kecerdasan emosi dan pola asuh demokratis maka akan semakin tinggi pula strategi coping adaptif mahasiswa. Berdasarkan hasil penelitian ini, maka hipotesis yang diajukan dinyatakan diterima. Ada hubungan positif yang signifikan antara kecerdasan emosi dengan pola asuh demokratis pada mahasiswa di Fakultas Psikologi Universitas Medan Area dengan sumbangan 87,6\%. Ada hubungan positif yang signifikan antara pola asuh dengan strategi coping adaptif mahasiswa, dengan sumbangan efektif yang didapatkan sebesar 84,6\%. Total sumbangan efektif dari kedua variabel bebas ( kecerdasan emosi dan pola asuh demokratis) terhadap strategi coping adaptif adalah sebesar 93,3\%. Dari hasil ini diketahui bahwa masih terdapat $6,7 \%$ sumbangan dari faktor lain terhadap strategi coping adaptif. Hasil lain diperoleh dari penelitian ini yakni, diketahui bahwa subjek penelitian ini para mahasiswa tingkat akhir di fakultas psikologi Universitas Medan Area, memiliki kecerdasan emosi dan pola asuh demokratis yang diperoleh tergolong tinggi. Hal ini dapat diketahui dengan melihat perbandingan nilai rata-rata/ mean empirik dan nilai rata-rata/ mean hipotetiknya.

\section{DAFTAR PUSTAKA}

Adi, T.N. (2010). Perilaku Coping Mahasiswa dalam Mengatasi Stres Mengikuti Mata Kuliah MPK Kuantitatif. Jurnal Acta Diurna Vol. 6 No. 2.

Aldwin, C. M. (1994). Stress, Coping, and Development: An Integrative Perspective. New York: Guilford Publications, Inc.

Arikunto, S. (2002). Prosedur Penelitian Suatu Pendektan Praktek. Yogyakarta. Rineka Cipta.

Azwar, S. (2003). Reliabilitas dan Validitas Alat ukur. Yogyakarta. PustakaPelajar.

Berzonsky, D, M. (1981). Adolescent Development. New York. Mac MillanPublishing.

Billings, A.G., \& Moos, R.H. (1984). Coping, Stress and Social Resources AmongAdulths With Unipolar Depression. Journal of Personality and Social Psychology. Vol. 46, No. 4, 877-891.

Breakwell, G. M, (1998). Coping with aggressive Behaviour. Yogyakarta. Kanisius.

Carver, C. S., Scheier, M., \& Weintraub, J. K. (1989). Assessing Coping Strategies: A Theoretically Based Approach. Journal of Personality and Soial Psyhology, 56(2), 267-283.

Chaplin, J.P. (2009). Kamus Lengkap Psikologi, (Terjemahan Kartini dan Kartono). Jakarta: Raja Grafindo Persada.

Conger, J, J. (1977). Adolescence and Youth. Physicological Development and Life Plan Maturity: A Comparison of Women Athletes and Non Athletes. Sex Role Journa. Voll : 43; 3.

Cooper, R, K. (2002). Executive EQ : Kecerdasan Emosi Dalam Kepemimpinan dan Organisasi. Jakarta. Gramedia Pustaka Utama. 
Daniel, G., (2001). Kecerdasan Emosional. Yogyakarta. Pustaka Umum.

Djamarah, S.B. (2001). Psikologi belajar. Edisi II. Jakarta: PT Rineka Cipta.

Dwi Fitri Hartaty, Azhar Azis, (2014) Hubungan Antara Pola Asuh Otoritarian Dan Konformitas Teman Sebaya Dengan Kenakalan Remaja, Analitika: 6 (1): 1-8

Folkman, S., Lazarus, R. S., Dunkel-Schetter, C., DeLongis, A., \& Gruen R. J. (1986). Dynamics of a Stressful Encounter: Cognitive Appraisal, Coping, and Encounter Outcomes. Journal of Personality and Social Psychology, 50(5), 992-1003.

Fuhrmann, B, S. (1990). Adolescence, Adolescent. Second edition. Glenview, Illionis : Scott, Foresman \& Company.

Hadi, S. (2002). Metodology Research II. Cetakan ke-27. Penerbit : Andi Offset.

Haditono, S. R, Knoers, A.M.P, \& Monks, F.J. (1994). Psikologi Perkembangan. Pengantar dalam Berbagi bagiannya. Cetakan Kesembilan. Yogyakarta. Penerbit : Gadjah Mada University Press.

Hamdani, R., Lahmuddin L., Aziz, A., (2015), Hubungan antara Dukungan Sosial dan Kecerdasan Emosional dengan Self-Regulated Learning Siswa. Analitika: 7 (2): 105-117

Harahap, E.R., Ferry N., Gustiarti L., (2014), Peranan Kohesivitas Kelompok Dan Kecerdasan Emosional Terhadap Organizational Citizenship Behavior, Analitika: 6 (1): 1-10

Hasmayani, B., Hotman S., (2012), Perbedaan Minat Sekolah dan Motivasi belajar Ditinjau dari Pola Asuh Orangtua, Analitika: 4 (1): 24-30

Hurlock, E. (1994). Psikologi Perkembangan. Suatu Pendekatan Sepanjang Rentang Kehidupan. Edisi kelima. Jakarta. Penerbit Erlangga.

Intani, F.S. \& Surjaningrum, E.R. (2008), Coping Strategi Pada Mahasiswa Salah Jurusan. Jurnal INSAN vol 12. No.02.

Isnainy, A.A. \& Alfita, L. (2017). Perbedaan Coping Stress Penderita Kanker Ditinjau dari Jenis Kelamin di RSUP H. Adam Malik Medan, Jurnal Diversita, 3 (1): 1-9.

Jaya, M. K., Mulyadi, D., Suleman, E. (2012). Pengaruh Kecerdasan Emosional Terhadap Kinerja Pada Kantor Kementrian Agama Kabupaten Karawang. Jurnal Manajemen vol 10. No 01.

Keliat, B. A. (2001). Penatalaksanaan stres. Jakarta: Penerbit Buku Kedokteran EGC.

Lazarus, R. S, and Folkman, S. (1985). Stres, Appraisal, and Coping. New York: Springer.

McCrae, R.R. (1984). Situasional Determinant of Coping Responses: Loss, Threatand Challenge. Journal of Personality and Social Psychology, Vol. 46,No. 4, 919-928.

Mussen, P. H. (1960). Handbook of Research Methods Child Development.First edition. John Willey \& Sons, Inc. New York.

Novita, E., (2012), Perbedaan Agresivitas Ditinjau dari Pola Asuh Orang Tua, Analitika: 4 (2): 53-56

Pandia, W.H, Abdul M., Azhar A., (2015) Hubungan Harga Diri Siswa dan Pola Asuh Demokratis Orangtua dengan Motivasi Belajar Siswa, Analitika: 7 (2): 80-87

Patton, P. (2002). EQ : Pengembangan Sukses Lebih Bermakna. Jakarta : Mitra Media Publishers.

Pestonjee, D.M. (1992). Stress And Coping. London; Sage Publications.

Pikunas, J. (1976). Human Development : an Emergent Science. Third edition. Tokyo. McGraw- Hill Kogakusha, LTD.

Pramadi, A. \& Lasmono, H. K. (2003). Koping Stres Pada Etnis Bali, Jawa, dan Sunda. Indonesian Psychological Journal. Anima. Vol. 18, No. 4, 326-340.

Rogers, R.W. \& Rippetor, P.A. (1987). Effects of Components of probection -Motivation Theory on Adaptive and Maladaptive Coping with a HealthThreat. Journal of Personality and Social Psychology. Vol. 52, No.3, 596-604.

Salamiah S, N.S., Dini H.S., (2011), Hubungan Intelegensi Dan Pola Asuh Orangtua Demokratis Dengan Harga Diri Siswa, Analitika: 3 (2): 99-114

Syarifah, Nefi D., (2010), Pengaruh Locus Of Control dan Kecerdasan Emosional terhadap Kemampuan Memecahkan Masalah pada Remaja Desa Percut Kecamatan Percut Sei Tuan, Analitika: 2 (2): 88-98

Zuraida, Kaiman T, Sri S, (2015), Hubungan Kecerdasan Emosional dan Dukungan Sosial Keluarga dengan Burnout, Analitika: 7 (2): 141-149 